\section{AB014. Developing}

\section{classification criteria for skin-} predominant dermatomyositis: assessing the methodology of the prospective validation study

\author{
Josef Symon S. Concha ${ }^{1,2}$, Joseph F. Merola ${ }^{3}$, \\ David Fiorentino ${ }^{4}$, Jan Peter Dutz ${ }^{5}$, Mark Goodfield ${ }^{6}$, \\ Filippa Nyberg ${ }^{7}$, Beatrix Volc-Platzer ${ }^{8}$, \\ Manubo Fujimoto ${ }^{9}$, Chia Chun Ang ${ }^{10}$, \\ Victoria P. Werth ${ }^{1,2}$
}

${ }^{1}$ Corporal Michael J. Crescenz VAMC, Philadelphia, PA, USA; ${ }^{2}$ Department of Dermatology, Perelman School of Medicine at the University of Pennsylvania, Philadelphia, PA, USA; ${ }^{3}$ Department of Dermatology, Brigham and Women's Hospital and Harvard Medical School, Boston, MA, USA; ${ }^{4}$ Department of Dermatology, Stanford University School of Medicine, Palo Alto, CA, USA; ${ }^{5}$ Department of Dermatology and Skin Science, University of British Columbia, Vancouver, BC, Canada; ${ }^{6}$ Department of Dermatology, Leeds General Infirmary, Leeds, UK; ${ }^{7}$ Karolinska University Hospital, Uppsala, Sweden; ${ }^{8}$ Department of Dermatology, Wiener Krankenanstaltenverbund, Vienna, Austria; ${ }^{9}$ Department of Dermatology, University of Tsukuba, Tsukuba, Japan; ${ }^{10}$ Department of Dermatology, Changi General Hospital, Singapore

Correspondence to: Victoria P. Werth. Department of Dermatology, Perelman Center for Advanced Medicine, Suite 1-330A, 3400 Civic Center Boulevard, Philadelphia, PA 19104, USA.

Email: werth@pennmedicine.upenn.edu.

\begin{abstract}
The Dermatomyositis Delphi Criteria Project created 25 provisional clinical, laboratory and contextual classification criteria after an extensive literature search, three rounds of consensus exercises and nominal group discussions. These criteria will be subjected to a case-control validation
\end{abstract}

study to create a combination of items that will define a more inclusive cohort of DM patients with skin-predominant disease for clinical research. Several measurement properties that need to be assessed prior to the conduct of a multicenter prospective validation study include the final purpose of the criteria set, population and disease characteristics of cases and controls for study entry, sources of samples, definition of criteria items, methods of item ranking and reduction, and consideration of criteria set validity against a comparator backdrop "gold standard" criteria. An expert committee Delphi and several online discussions among participants from the fields of dermatology, and adult and pediatric rheumatology have been conducted in order to address such issues. Constant evaluation of the methodologic process is vital to produce classification criteria which are valid and reliable to identify patients with DM and delineate these patients from those with mimicker diseases.

Keywords: Dermatomyositis; amyopathic; skin-predominant; classification; criteria

doi: 10.21037/atm.2021.AB014

Open Access Statement: This is an Open Access article distributed in accordance with the Creative Commons Attribution-NonCommercial-NoDerivs 4.0 International License (CC BY-NC-ND 4.0), which permits the noncommercial replication and distribution of the article with the strict proviso that no changes or edits are made and the original work is properly cited (including links to both the formal publication through the relevant DOI and the license). See: https://creativecommons.org/licenses/by-nc-nd/4.0/.

Cite this abstract as: Concha JSS, Merola JF, Fiorentino D, Dutz JP, Goodfield M, Nyberg F, Volc-Platzer B, Fujimoto M, Ang CC, Werth VP. Developing classification criteria for skinpredominant dermatomyositis: assessing the methodology of the prospective validation study. Ann Transl Med 2021;9(5):AB014. doi: 10.21037/atm.2021.AB014 